acute traumatic intracranial haematoma at all ages. Children with head injury can be managed by guidelines similar to those already used in adults, but to improve outcome even more patients should be investigated by computed tomography soon after injury. We therefore recommend that a patient with head injury who has either a persisting alteration in conscious level or a skull fracture should be investigated by computed tomography. The figure shows how this might be achieved through coordinated efforts by neurosurgical units and general hospitals with facilities for computed tomography. The box shows guidelines proposed as a basis for formulating new, locally agreed criteria for managing children and adults with head injuries.

This work was supported by the Medical Research Council and the chief scientist, Scottish Home and Health Department. We thank our colleagues for allowing us to use their original data.

1 Teasdale G, Galbraith S, Murray L, et al. Management of traumatic intracranial haematoma. Br Med $\mathcal{f}$ 1982;285: 1695-7.

2 Rockswold GL, Leonard PR, Naquib MG. Analysis of management in thirty threeclosed head injury patients who "talked and deteriorated." Neurosurgery 1987;21:51-5.

3 Mendelow AD, Teasdale G, Jennett B, et al. Risks of intracranial haematoma in head injured adults. Br Med 7 1983;287:1173-6.

4 Briggs $M$. Clarke P, Crockard A, et al. Guidelines for initital management after head injury in adults. Suggestions from a group of neurosurgeons. $B$ Med f 1984;288:983-5.

5 Brookes $M$, MacMillan R, Cully S, et al. Head injuries in accident/emergency departments. How different are children from adults? $\mathcal{F}$ Epidemiol Community Health (in press)

6 Strang I, MacMillan R, Jennett B. Head injuries in accident and emergency departments at Scottish hospitals. Injury 1987;10:154-9.

7 Swann I, MacMillan R, Strang I. Head injuries at an inner city acciden department. Injury 1982;12:274-8.

8 Jennett B, Macmillan R. Epidemiology of head injury. Br Med $\mathcal{J}$ 1981; 282:101-7.

9 Thillainayagam K, MacMillan R, Mendelow AD. How accurately are fractures of the skull diagnosed in an accident and emergency department? fractures of the skull digr
Injury 1987;18:319-21.

10 Teasdale G, Jennett B. Assessment and prognosis of coma after severe head injury. Acta Neurochir(Wien) 1976:34:45-55.
11 Morris JA, Gardner MJ. Calculating confidence intervals for relative risks odds ratios) and standardised ratios and rates. Br.Med f 1988;296:1313-6. Bishop YMM, Fienberg SE, Holland PW. Discrete multivariate analysis. Cambridge: Massachusetts Institute of Technology: Press, 1975.

13 Galbraith SL. Age distribution of extradural haemorrhage without skull fracture. Lancet 1973;ii:1217-8.

14 Mazza D, Pasqualin A, Feriott IG, Dapian R. Traumatic extradural haematomas in children: experience with 62 cases. Acta Neurochir (Wein) 1982;65:67-80.

15 Dhellemnes P, Legaine JP, Christiaens JL, et al. Traumatic extradural hematomas in infancy and childhood. I Neurosurg 1985;62:861-4.

6 Leggate JRS, Lopez-Ramos N, Genitori L, et al. Extradural haematoma in infants. British Yournal of Neurosurgery 1989;3:533-41.

17 Servadei F, Ciucci G, Morichetti A, et al. Skull fracture as a factor of increased risk in minor head injuries. An indication for a broader use of cerebral CT scanning. Surg Neurol 1988:30:364-9.

18 Rosenthal BW, Bergman I. Intracranial injury after moderate head trauma in children. I Pediatr 1989;115:346-50.

19 Dershewitz RA, Kaye BA, Swisher CN. Treatment of children with post traumatic loss of consciousness. Pediatrics 1983;72:602-7.
traut

20 Snoek JW, Minerhoud JM, Wilmink JT. Delayed deterioration following mild head injury in children. Brain 1984;107:15-36.

21 Sainsbury CPQ, Sibert JR. How long do we need to observe head injuries in hospital? Arch Dis Child 1984;59:856-9.

22 Fowkes FGR, Evans RC, Williams LA, et al. Implementation of guidelines for the use of skull radiographs in patients with head injuries. Lancet 1984; ii: $795-7$.

23 Miller JD, Tocher JL, Jones PA. Extradural haematoma-earlier detection, better results. Brain Injury 1988;2:83-6.

24 Bowers SA, Marshall LF. Outcome in 200 consecutive cases of severe head injury treated in San Diego County: a prospective analysis. Neurosurg. 1980;6:237-42

25 Cordobes F, Lobato RD, Rivas JJ, et al. Observations on 82 patients with extradural hematoma. Comparison of results before and after the advent of extradural hematoma. Comparison of results before

26 Bricolo AP, Parker LM. Extradural haematoma: toward zero mortality. Neurosurgery 1984;14:8-12.

27 Klauber MR, Marshall LF, Iverssen TG, et al. Determinants of head injury mortality: importance of the low risk patient. Neurosurgery 1989;24:31-6.

28 Thornbury JF, Masters SJ, Campbell JA. Imaging recommendations for head trauma: a new comprehensive strategy. $A \mathcal{F} R$ 1987;149:781-3.

29 Leonidas JC, Ting W, Binkiewicz A, et al. Mild head trauma in children: when is a roentgenogram necessary? Pediatrics 1982;69:139-43.

30 Royal College of Radiologists. Patient selection for skull radiography in uncomplicated head injury. Lancet 1983; ; $115-8$.

31 Hewett RL, Wood VA. Availability of computed tomography of the brain in the United Kingdom. BrMed f 1989;298:1219-20.

32 Kohi YM, Mendelow AD, Teasdale GM, et al. Extracranial insults and outcome in patients with acute head injury-relationship to the Glasgow outcome scale. Injury 1984;16:25-9.

33 Gentleman D, Jennett B. Hazards of inter-hospital transfer of comatose head injured patients. Lancel 1981;ii:853-5.

(Accepted 1/ December 1989)

\section{Comparison of visual and radiographic detection of bony changes at the knee joint}

\section{Juliet Rogers, Iain Watt, Paul Dieppe}

Rheumatology Unit, Bristol Royal Infirmary, Bristol BS2 8HW

Juliet Rogers, $\mathrm{MB}$, lecturer in palaeopathology

Iain Watt, FRCR, consultant radiologist

Paul Dieppe, FRCP, professor

Correspondence to: Dr Rogers.

BrMed $\mathcal{F}$ 1990;300:367-8
Osteoarthritis is often reported in human bones recovered from archaeological sites. The diagnosis is usually based on the presence of osteophytes with or without surface pitting, eburnation, or change of contour of the bony articular surface.' Clinicians diagnose osteoarthritis largely on the basis of changes visible on radiography, including narrowing at the joint space, osteophytes, subchondral eburnation, and cysts. ${ }^{2}$ The sensitivity of radiography in detecting pathological changes in bone has not been examined but is important in several disciplines. We investigated this by examining 24 knee joints visually and radiographically for changes compatible with osteoarthritis.

\section{Methods and results}

We selected 24 knee joints from 14 skeletons with a range of changes induced by osteoarthritis (normal to severe). The joints were assessed visually by a palaeopathologist (JR), who graded any osteophytes, eburnation, pitting, and alteration of bony contour as 1 (mild), 2 (moderate), or 3 (severe). Charts were drawn to show the extent and distribution of the changes, and the bones were photographed. The bones were then aligned in the anatomical position, and an anteroposterior radiograph was taken (the joint space, obviously artificial, was not included in the assessment). The $x$ ray films were examined by a radiologist (IW), who was unaware of the visual findings. Any osteophytes and other changes caused by osteoarthritis were graded as above. The visual and radiographic assessments were then compared (figure).

Eight of the 24 knee joints were normal by both techniques. Changes were noted on visual assessment in 16 but radiographically in only two. Osteophytes alone were detected visually in 11 knees (seven grade 1 , three grade 2 , and one grade 3 ), but only one of these knees was abnormal on radiography. Severe osteophytosis with other bony changes was seen in five knees, two of which had severe eburnation on the articular surface; one of these joints showed evidence of osteoarthritis on radiography.

\section{Comment}

We chose to study the knee joint because it is the commonest site for osteoarthritis and because we could obtain $x$ ray films of the disarticulated bones in the anatomical position fairly easily. We could not obtain satisfactory lateral $x$ ray films because of difficulties with alignment, so the study compared visual inspection of all aspects of the tibia and femur with a single anteroposterior radiograph. The comparison, however, was acceptable: palaeopathologists rely on looking at the whole area of the joint, whereas clinicians use an anteroposterior radiograph as their main aid to diagnosing osteoarthritis. The discrepancy between visual 

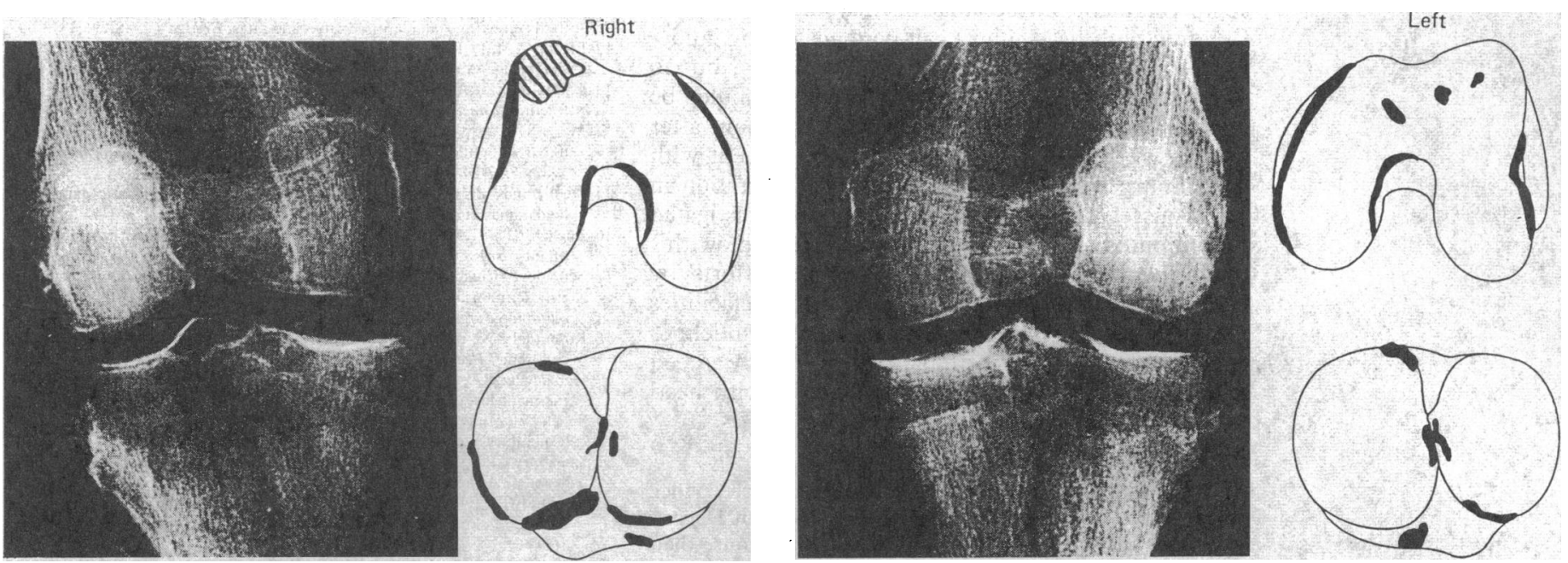

Comparison of radiograph and visual assessment of one pair of knee joints, showing extensive eburnation (hatched area) and severe osteophytosis (solid lines) Radiograph appears normal and $x$ ray findings was striking. Severe osteophytosis and eburnation were often not visible in $x$ ray films even when these were re-examined with hindsight.

The frequency with which osteoarthritis is reported in archaeological material and current figures for the prevalence of the disease ${ }^{3}$ are often compared. The different sensitivity of the methods used to make a diagnosis, shown by this study, and the fact that palaeopathologists often equate osteophytosis with osteoarthritis ${ }^{4}$ make such a comparison misleading. In our study 11 of 24 knee joints had osteophytes alone and a further five had other visual changes compatible with osteoarthritis. Thus the prevalence of osteoarthritis could have been reported as $67 \%$ or $21 \%$ depending on the diagnostic criterion used. Only two of the 24 knee joints were abnormal on radiography, one of which was thought to have changes due to osteoarthritis (4\%). Large osteophytes and areas of eburnation, particularly if on the patella groove of the femur or the anteroposterior aspects of the tibio- femoral joint, were often invisible in the radiograph. This suggests that radiography is a poor method of detecting osteoarthritis. It may also partly explain the discrepancy between changes seen in radiographs and symptoms found in epidemiological studies and the difficulties of developing diagnostic criteria for osteoarthritis of the knee. ${ }^{5}$ Areas of osteophytosis or focal osteoarthritis may cause symptoms or functional problems but remain invisible to clinicians or radiologists.

1 Rogers J, Waldron T, Dieppe PA, Watt I. Arthropathies in paleopathology: the basis of classification according to most probable causes. Fournal of Archaeobasis of classification according

2 Kellgren JH, Lawrence JS. Radiological assessment of osteoarthritis. Ann Rheum Dis 1957;16:494-502.

3 Rogers J, Watt I, Dieppe P. Arthritis in Saxon and mediaeval skeletons. BrMed f 1981;283:1668-71.

4 Clarke GA, Delmond JA. Vertebral osteophytosis in Dickson mound populations: a biomechanical interpretation. Henry Ford Hosp Med f 1979;27:48-54. 5 McAlindon T, Dieppe PA. Osteoarthritis: definitions and criteria [Editorial] Ann Rheum Dis 1989;48:531-2.

(Accepted 9 November 1989)

\section{Effect of non-steroidal anti-inflammatory drugs on dyspeptic symptoms}

\section{T M Shallcross, R V Heatley}

Department of Medicine, St James's University Hospital, Leeds LS9 7TF T M Shallcross, MRCP, research fellow

R V Heatley, FRCP, senior lecturer in medicine

Correspondence to: Dr Shallcross.

$\operatorname{Br} \operatorname{Med} \mathcal{f} 1990 ; 300: 368-9$
The association of non-steroidal anti-inflammatory drugs with the lifethreatening complications of peptic ulceration is well documented.' Elderly patients with peptic ulceration are less likely to complain of dyspepsia if they are using these drugs. ${ }^{2}$ As dyspeptic symptoms are a major indication for gastroscopy we investigated whether their diagnostic importance may be altered in patients taking non-steroidal anti-inflammatory drugs, which could lead to delay in the diagnosis of peptic ulceration.

\section{Patients, methods, and results}

We studied 149 consecutive patients with dyspepsia referred to an open access endoscopy clinic by rheumatologists $(22 \%)$ and general practitioners. Before endoscopy patients were interviewed with a structured questionnaire about their symptoms and use of non-steroidal anti-inflammatory drugs. Dyspepsia was broadly defined as pain, discomfort, or burning in the middle or upper part of the stomach or the lower chest, and patients who had angina were excluded. Statistical analysis was by the $\chi^{2}$ test with Yates's correction. The ratio of the prevalence of a symptom in patients with ulcers to the prevalence in those without ulcers was used to indicate the diagnostic importance of the symptom (table).

Fifty patients had taken non-steroidal anti-inflammatory drugs regularly during the month before endoscopy. Forty eight patients had peptic ulcers (seven oesophageal, 18 gastric, 21 duodenal, and two gastric and duodenal). Among the patients who had not taken non-steroidal anti-inflammatory drugs pain that woke them at night was significantly more common in those with ulcers $(67 \% v 29 \%, \mathrm{p}=0.003)$, whereas among those who took non-steroidal antiinflammatory drugs this symptom was less common in those with ulcers ( $38 \% v 46 \%)$; the difference between the two groups with ulcers was also significant $(p=0 \cdot 041)$. Localised epigastric pain was not significantly associated with ulceration in those who had not used non-steroidal anti-inflammatory drugs $(30 \% v$ $20 \%$ ) but showed a significant negative association with peptic ulcer in the group who had used these drugs $(14 \% v 58 \%, \mathrm{p}=0.004)$. Among the patients without ulceration localised epigastric pain was significantly more common in those taking non-steroidal antiinflammatory drugs $(58 \% v 20 \%, \mathrm{p}=0 \cdot 004)$. Considerable differences in the diagnostic implications of other symptoms were seen. In particular, pain occurring before meals or when the patient was hungry and loss of $\geqslant 3 \mathrm{~kg}$ in weight during the past six months showed a positive association with ulcers in those who had not taken non-steroidal anti-inflammatory drugs but a 